\title{
Commentary
}

\section{Visualizing Conflict: Possibilities for Urban Research}

\author{
Juan Francisco Saldarriaga *, Laura Kurgan and Dare Brawley \\ Center for Spatial Research, Columbia University, New York, NY 10027, USA; E-Mails: jfs2118@columbia.edu (J.F.S.), \\ ljk33@columbia.edu (L.K.), dare.brawley@columbia.edu (D.B.) \\ * Corresponding author
}

Submitted: 27 January 2017 | Accepted: 27 March 2017 | Published: 4 April 2017

\begin{abstract}
The Center for Spatial Research (CSR) is undertaking a multiyear project investigating what we have termed Conflict Urbanism. The term designates not simply the conflicts that take place in cities, but also conflict as a structuring principle of cities intrinsically, as a way of inhabiting and creating urban space. The increasing urbanization of warfare and the policing and surveillance of everyday life are examples of the term (Graham, 2010; Misselwitz \& Rieniets, 2006; Weizman, 2014), but conflict is not limited to war and violence. Cities are not only destroyed but also built through conflict. They have long been arenas of friction, difference, and dissidence, and their irreducibly conflictual character manifests itself in everything from neighborhood borders, to differences of opinion and status, to ordinary encounters on the street. One major way in which CSR undertakes research is through interrogating the world of 'big data.' This includes analyzing newly accessible troves of 'urban data,' working to open up new areas of research and inquiry, as well as focusing on data literacy as an essential part of communicating with these new forms of urban information. In what follows we discuss two projects currently under way at CSR that use mapping and data visualization to explore and analyze Conflict Urbanism in two different contexts: the city of Aleppo, and the nation of Colombia.
\end{abstract}

\section{Keywords}

conflict; data; data visualization; GIS; interactive; mapping; urbanism

\section{Issue}

This commentary is part of the issue "Urban Forms and Future Cities", edited by Luca D'Acci (Erasmus University Rotterdam, The Netherlands), Tigran Haas (KTH Royal Institute of Technology, Sweden) and Ronita Bardhan (Indian Institute of Technology Bombay, India)

(C) 2017 by the authors; licensee Cogitatio (Lisbon, Portugal). This article is licensed under a Creative Commons Attribution 4.0 International License (CC BY).

\section{Visualizing to Understand Complexity in Colombia}

At first glance it is extremely difficult to grasp the scope of the Colombian conflict: it spans more than 50 years and covers most of the country's territory, it even crosses its borders into neighboring Ecuador, Venezuela, Peru and Brazil; it includes multiple actors, both from the right and from the left, who at times fought against and at times profited from the illegal drug business; it has been shaped and re-shaped by a multiplicity of political and socio-economic forces, and has generated millions of victims of displacement, homicide, massacres and sexual violence. More recent developments include a long and controversial demobilization process by the right-wing paramilitary groups, and the current peace process with the left-wing guerrillas of the FARC, which have polarized the country. The most recent peace accord has been in the making for more than four years and produced an agreement that was signed by the government and the FARC and then rejected by the Colombian people through a referendum, only to be modified and approved again by members of the Colombian legislative body.

As part of this ongoing peace process the Unidad para la Atención y Reparación Integral a las Víctimas, an agency within the Colombian Government, has been dedicated to assembling a database of victims of the conflict: the Registro Único de Víctimas. This massive dataset reflects the stories of nearly eight million Colombian cit- 
izens, who volunteered information in hopes of someday receiving reparations. It is doubtful that the dataset is complete, but it is still a remarkable repository of information about who has been impacted by the conflict, the kinds of crimes committed at different points in time, and where people have been displaced to and from.

This project uses techniques of mapping and data visualization to understand spatial and temporal patterns of the conflict as well as the limits and gaps embedded in the data. How has the conflict impacted urban development in Colombia? Do particular types of crime form spatial concentrations? How have internally displaced peo- ple moved throughout the country? Have cities of all sizes had to bear the burden of massive influxes of displaced people equally? Are there spikes that expose bias in the data collection? Through an iterative process the project has used spatial analysis and visualization to address these questions and prompt others for further research to build a nuanced understanding of the conflict.

Figure 1, for example, shows internally displaced people in Colombia, from 1985 to 2015. The thickness of the lines represents the number of people who were displaced-the thinnest lines represent fifty people and the thickest more than 10,000 . The color within each

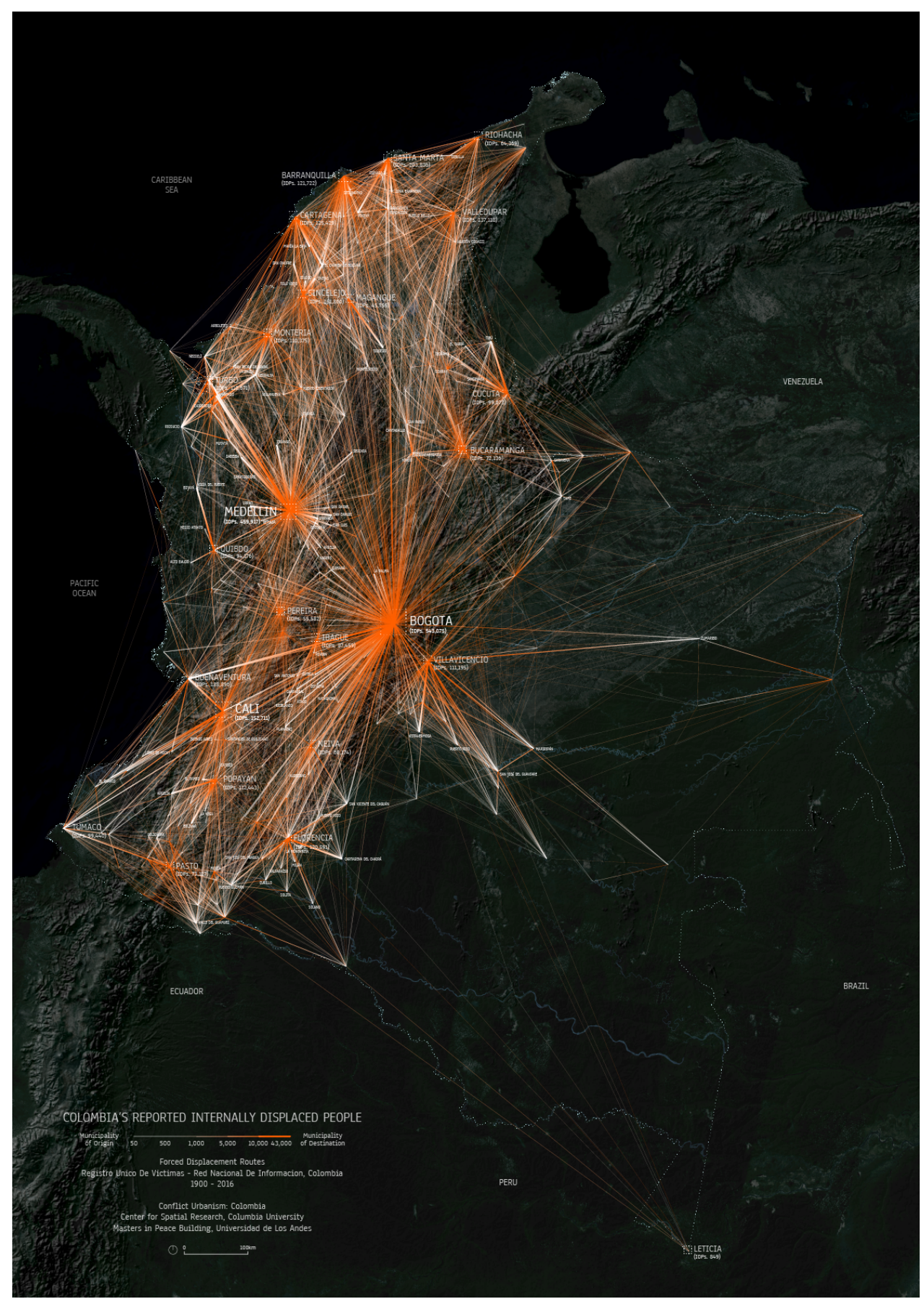

Figure 1. Map of Internally Displaced People 1985-2015. 
line represents direction of movement-the white ends of the line represent origins of displacement and the orange destination ${ }^{1}$. The map shows well known facts about the conflict: the large numbers of people who were displaced from small towns and moved to large cities, like Bogotá, Medellín or Cali; it also shows the more than 20,000 people that were displaced before, during and after the most infamous massacres of the conflict: the attack on Bojayá by the FARC, or the repeated massacres around La Gabarra by the paramilitaries; it also reveals that the areas surrounding Medellín and Turbo saw more than half a million departures and arrivals. However, the map also highlights other aspects of the conflict that are not that well known or understood: it makes clear that municipalities like Florencia, Popayán or Pasto in the southwest received almost 300,000 displaced people; that over 15,000 people have been forcibly displaced from Buenaventura to Cali and, almost 50,000, from Buenaventura to Bogotá; and that all the main cities along the Atlantic coast have served as destinations for more than 350,000 displaced people. It even shows how remote and sparsely populated municipalities like Leticia in the south or Puerto Inírida in the east have also suffered displacement.

The map powerfully reveals how the conflict has enveloped the whole country in a deep and intricate web of displacement and violence. While this visualization conveys the complexities of the war as a whole, it does not show the stories of individual displacement events or speak to the number of displacements that have occurred from the country side to the cities or within small and medium-sized municipalities.

A second type of visualization, in the form of a video animation (Figure 2), begins to reveal these finer grain histories captured by the Registro Único de Víctimas: this video uses a simple particle system to illustrate every single displacement in the dataset from 1985 to $2015 .^{2}$ The advantage of showing this information in video form is that it allows us to display a rather complex dataset in a single diagram while still conveying a sense of dynamism that a static graph cannot produce. The animation shows how in the late 1980s and early 1990s displacement was mostly confined to the regions around Medellín and Urabá, and how starting in the late 1990s there was not just an increase in the number of displaced people but an expansion of forced displacement to the rest of the country. By the mid 2000s the visualization clearly shows how the whole country is covered in forced displacement and the south-west of the country has also become a center for this type of violence.

In addition, this type of visualization allows us to zoom into specific moments and places in the conflict while still providing relevant contextual information through text annotations. For example, we can see the exact moment in which the FARC attacked Mitú displacing more than 1,000 of its inhabitants, killing almost 150 and kidnapping more than 100 people; or the permanent flow of displacement that has been going on from Buenaventura to Cali and Bogotá since 2013.

\section{A Multilayered Approach to Detecting Urban Damage: Aleppo, Syria}

The city of Aleppo fell to Syrian government forces and their allies in December 2016. Hundreds of thousands of Syrians have been killed or injured, and an estimated nine million people displaced. Aleppo has suffered extensive physical damage - to its symbolic center, the Citadel; its surrounding heritage sites, which mark ancient empires, diverse religions, and multiple cultures and trade

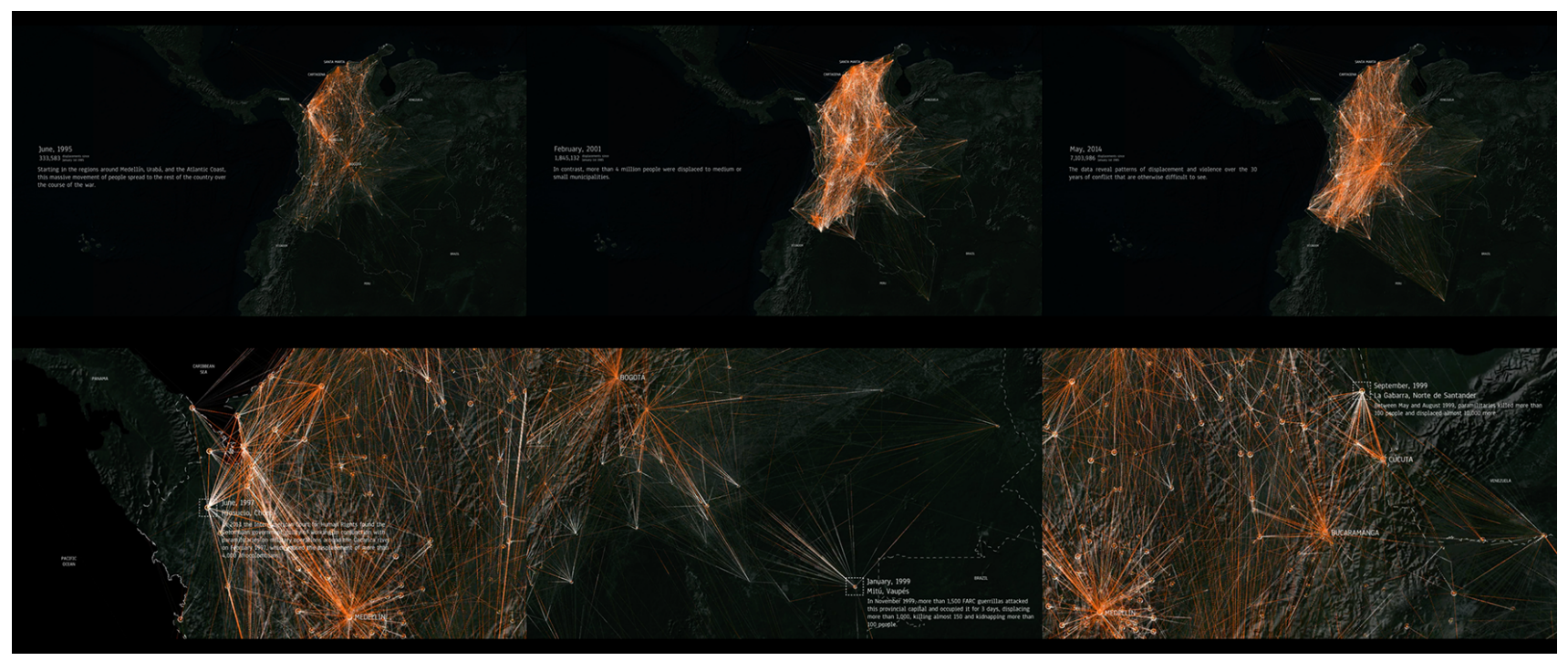

Figure 2. Screenshots of animation (zoomed out and in).

\footnotetext{
${ }^{1}$ View and interactive version of this map at http://c4sr.columbia.edu/conflict-urbanism-colombia.

2 This animation can be viewed at http://c4sr.columbia.edu/conflict-urbanism-colombia.
} 
routes; and to its eastern and southern neighborhoods. The destruction of the city's cultural and urban history, as well as its cultural memory and identity, appears to be an intentional result of military operations, and not merely a byproduct of them.

The focus of this work has been on the city of Aleppo, on urban damage, and on how the city became an integral part of the infrastructure of conflict. We have created an archive and a resource, which we hope will become useful in the years to come, as a framework for documenting crimes of war, as well as for speculating about how Aleppo might be rebuilt.

Unlike the work on Colombia, much of the focus on Aleppo has revolved around how to create spatial datasets where they did not previously exist. To facilitate our work we created an interactive map of the city of Aleppo, which combines layers of high-resolution satellite images together with data gathered by UNITARUNOSAT (the United Nations Institute for Training and Research Operational Satellite Applications Programme), to show the historic city, and damages incurred to it, from 2012 to the present.

We followed this map with a series of case studies released over the course of 2016 in which we use the map, together with other data sources to examine specific moments in the war. This article focuses on the methods of observation and monitoring that the project has used to examine small-scale and city wide patterns of dam- age during the war: on the one hand the project uses the view from a distance with high and low-resolution satellites; and on the other it has archived thousands of on-the-ground videos captured by citizen-journalists and uploaded to YouTube. Using the logic of a typical geographic information system (GIS) map, the Conflict Urbanism: Aleppo project overlaps these different sources of material as layers for two purposes: first, to provide evidence about the physical destruction of the city, and second, to prototype different methods of observing and monitoring urban warfare from a safe distance.

The interactive map (Figure 3 ) assembles an archive of high resolution satellite images and allows users to navigate the city of Aleppo by neighborhood. ${ }^{3}$ Each pixel in these images captures just fifty centimeters on the earth's surface-the highest resolution available to civilians until recently. The branch of the UN dedicated to satellite research, UNITAR-UNOSAT, trains and assigns teams of people to manually examine images like these to identify and record sites damaged by bombs in war zones. The map allows users to view the data produced by UNITAR-UNOSAT about Aleppo and compare it to high resolution satellite images where this damage is visible from four days throughout the war.

Although we tend to take it for granted today, the high-resolution satellite technology and imagery that we make use of here, seen in Figure 4, was only declassified and made generally available a decade and a half ago

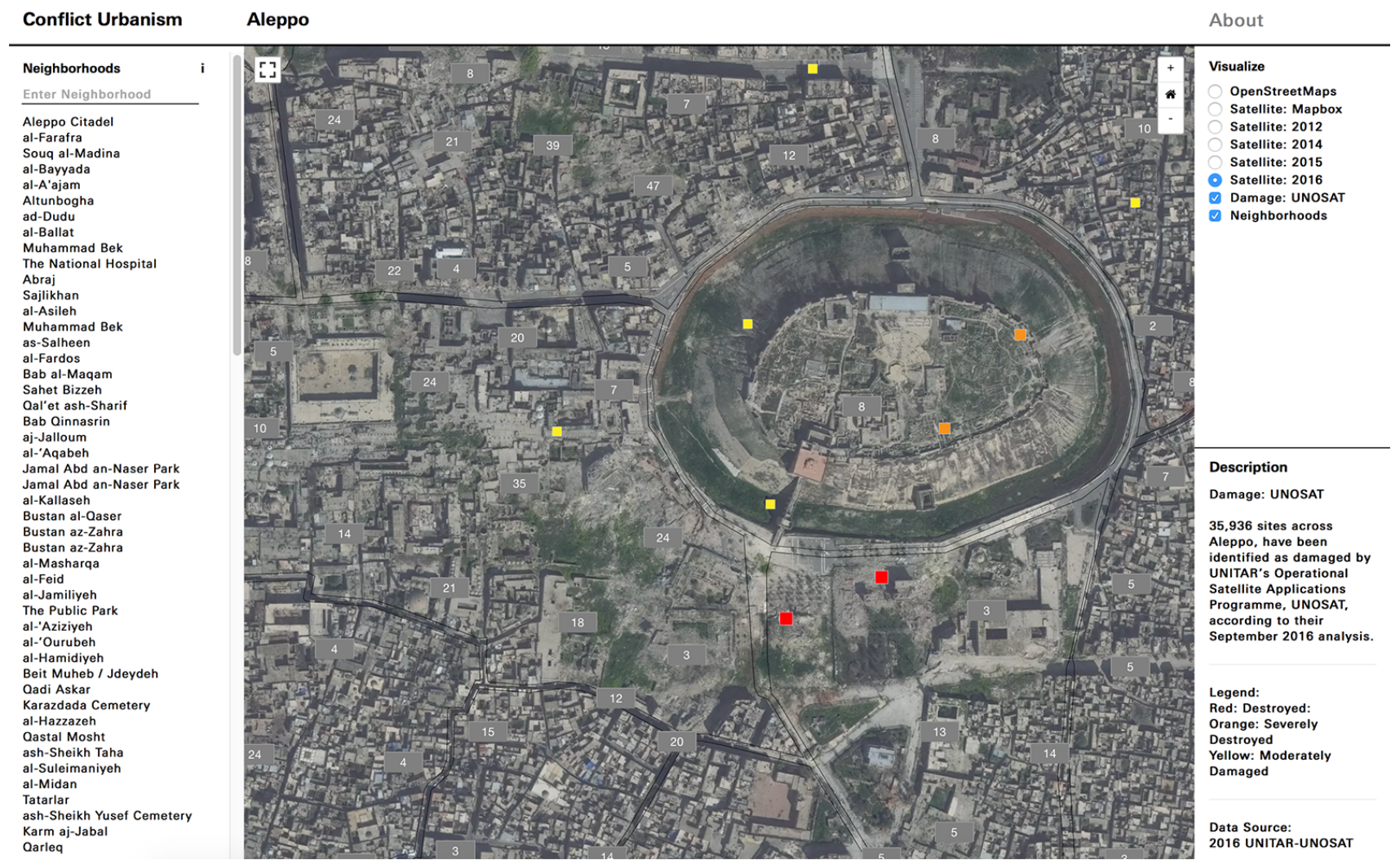

Figure 3. Interactive map of Aleppo that allows users to browse by neighborhood. Satellite images from World View II @ Digital Globe 2015 \& 2016.

\footnotetext{
${ }^{3}$ View the interactive map at http://c4sr.columbia.edu/conflict-urbanism-aleppo/map/index.html.
} 


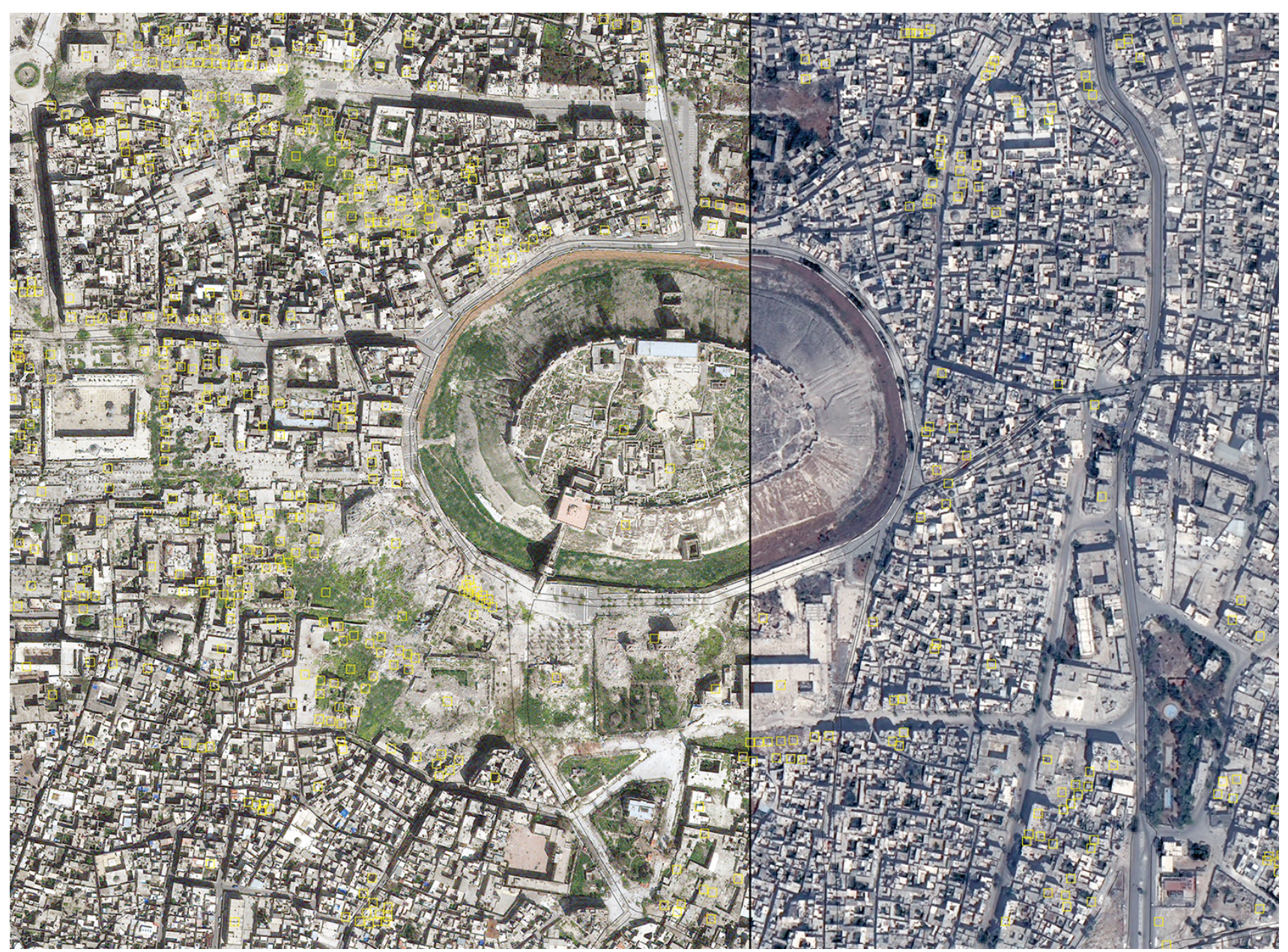

Figure 4. Two satellite images of Aleppo's Citadel and surrounding neighborhoods on March 23, 2016 (left) and September 3, 2015 (right). Yellow squares indicate damaged sites identified by the United Nations in May 2015. Additional unmarked damaged sites are also visible. Satellite images from World View II @ Digital Globe 2015 \& 2016.

(Cosgrove \& Fox, 2010; Kurgan, 2013). And while images become available for purchase by the public once they are captured, they are still expensive, costing between \$14 and \$18 per square kilometer.

Because of the cost of high resolution satellite images and the time required to analyze them manually, looking for damaged sites, UNITAR-UNOSAT has only collected data at four dates over the 5 years of war. Although their data is thorough, it was not updated on a regular basis, and, we saw a need to track urban damage more frequently than is possible using expensive and proprietary high resolution satellite images. In a collaboration with a remote sensing scientist the project took on an experimental approach to using low resolution, and free, images captured by the Landsat satellite to detect change in Aleppo every two weeks. ${ }^{4}$ This analysis has resulted in a dataset, created algorithmically, which can help identify areas over specific time periods that have been severely destroyed in the city. This approach measures changes in the brightness of pixels in the Landsat satellite images between two successive images. The result is messy and riddled with ambiguity (Figure 5), but has nonetheless led to new insights about the locations and rhythm of destruction in the city.

In order to ground-truth the results of this experimental approach, we did two things: first we overlaid the Landsat pixels (shown in yellow in Figure 6) onto high resolution satellite images from the same time frame; second we cross-checked it with YouTube videos, from the same date. In many cases the method was successful and revealed that the analysis of low resolution satellite images had been able to identify many areas of damage to large buildings and infrastructure.

YouTube has become one of the largest sources (and archives) of information about events on the ground in Syria: since January 2012 over a million videos of the conflict have been uploaded, with hundreds of millions of views to date. This independently reported footage has created a new powerful archive, but opens up crucial questions of credibility, verification, and bias. As with all data, every video comes to us bearing the traces of the situation and intentions that motivated its production. This does not disqualify it-quite to the contrary-but it does demand that we approach everything critically and

\footnotetext{
${ }^{4}$ Jamon Van Den Hoek, "Remote Sensing Urban Damage” in Conflict Urbanism Aleppo. http://c4sr.columbia.edu/conflict-urbanism-aleppo/remotesensing.html.
} 


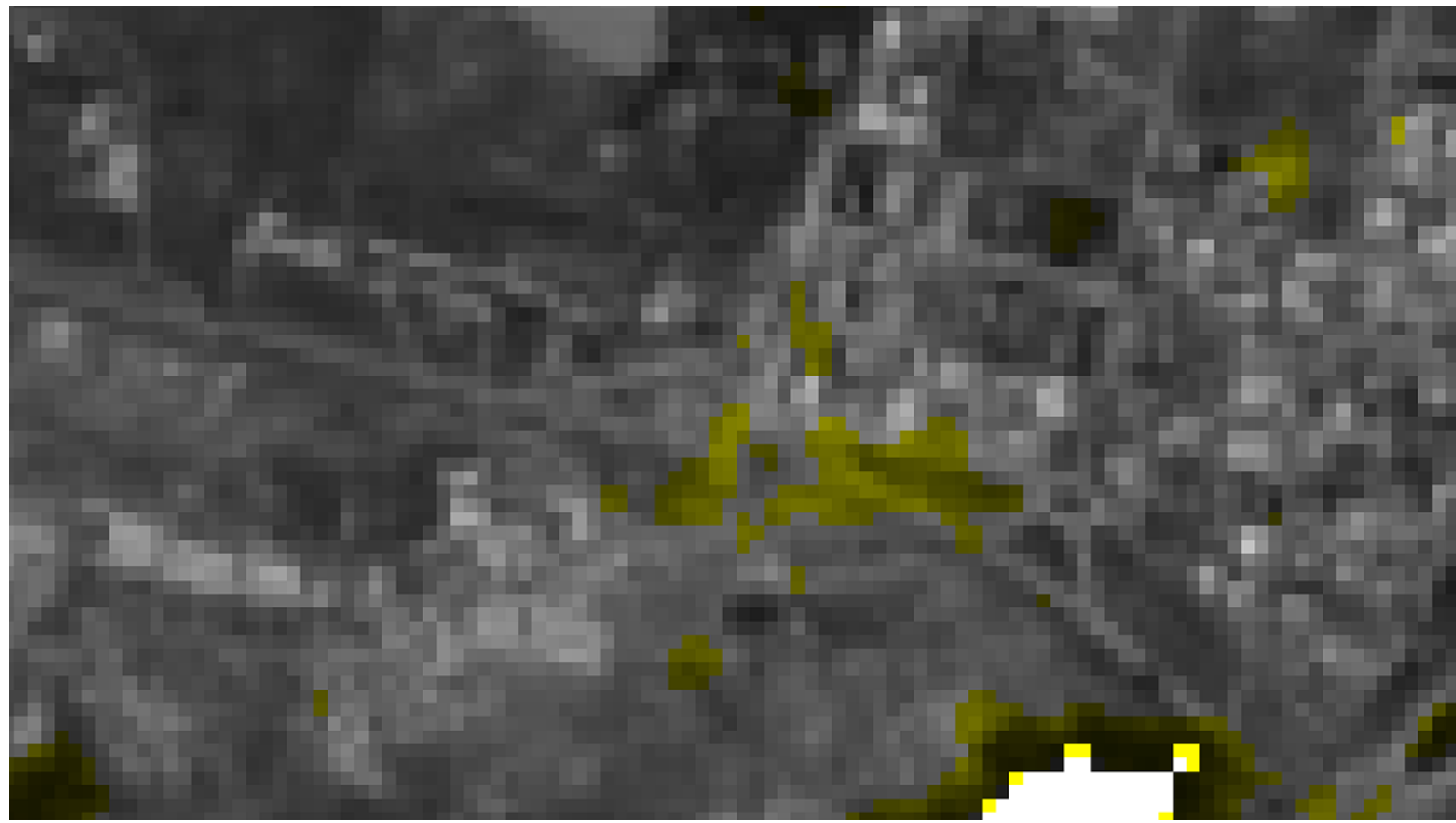

Figure 5. Landsat Image of Castello road on June 10, 2016 with areas of 'significant' pixel value change highlighted. Significant pixel change detection algorithm developed by Jamon Van Den Hoek.

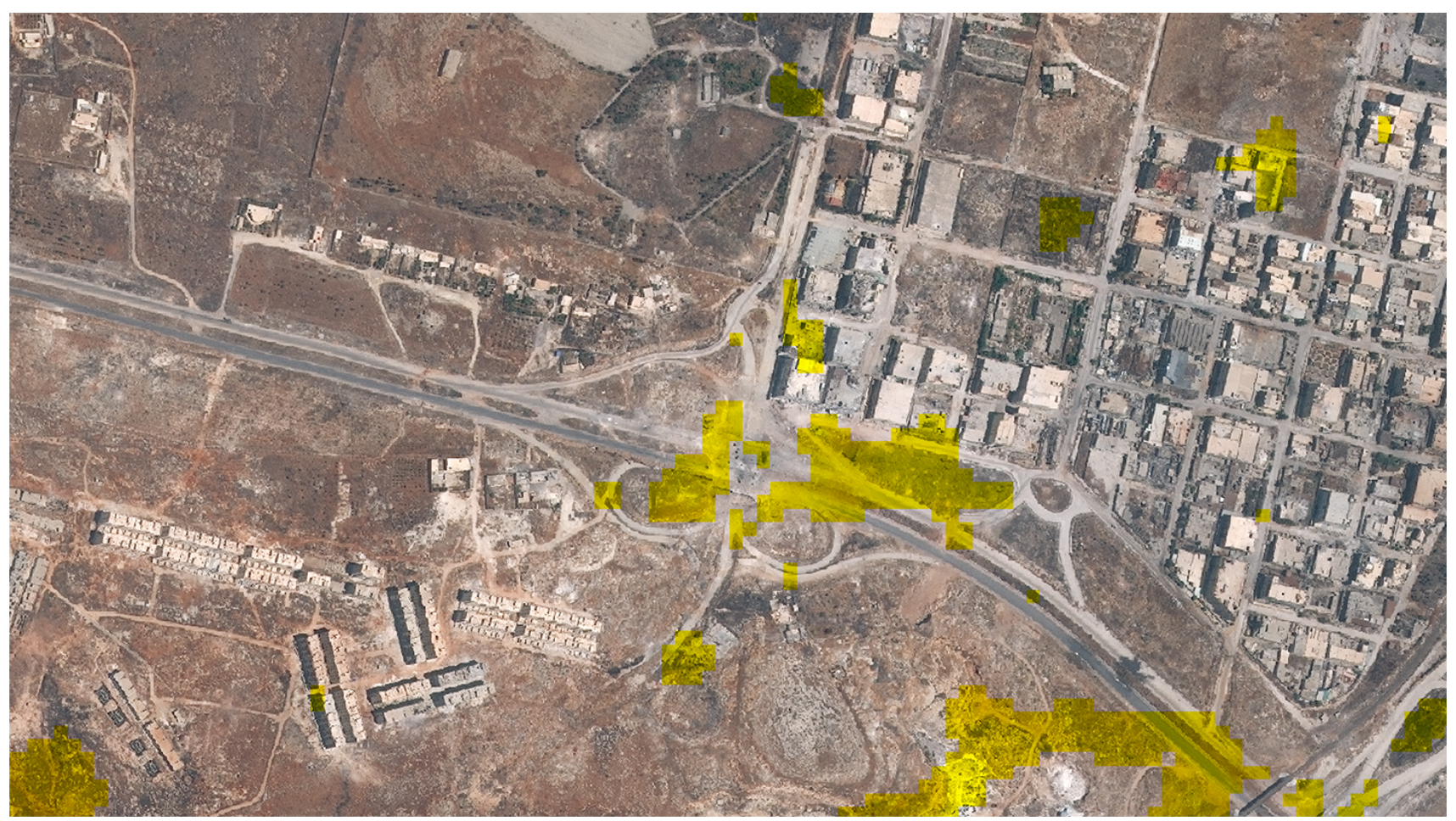

Figure 6. High resolution satellite image from June 11, 2016 (one day after the second Landsat image was taken) which shows major damage to Castello Road overpass as well as buildings in the surrounding area. Satellite images from World View II (C) Digital Globe 2015 \& 2016. Significant pixel change detection algorithm developed by Jamon Van Den Hoek.

carefully. The videos can be a key source to verify the location and date of events: major news agencies have come to rely on YouTube as a primary source for their reporting, and human rights organizations often cite videos as part of their advocacy and documentation efforts.
YouTube is not an inherently spatial data source. However, citizen journalists uploading these videos often included the names of the neighborhoods or landmarks depicted in their footage in the video titles. Because of this widespread naming convention, CSR was 
able to geolocate and map YouTube videos posted by three of the most highly cited channels posting videos about the conflict in Aleppo. This spatialized archive (Figure 7) has already assisted CSR research about Aleppo, and will hopefully help to further the use of YouTube videos in investigations about the war.

Through a multilayered approach the project uses these three modes of seeing Aleppo-triangulating between these different sources-to reveal astonishing city-wide and hyper-local patterns in the war. At the city scale: the high-resolution view and the data produced from it by UNITAR-UNOSAT shows that the vast majority of the damage was experienced by neighborhoods in the eastern and southern portions of Aleppo which were besieged by the Assad Regime during the fall of 2016. Narrative accounts through news reporting confirms this and these are also the areas of the city which have the most damage documented through YouTube videos. Together these sources of evidence show that this portion of the city was systematically bombed and shelled for the duration of the war. At the hyper local scale: a block of flattened buildings, a highway overpass dotted with massive holes caused by bombs, attacks on an access road which carried life critical supplies to rebel held areas of the city, and collapsed structures amidst dense residential neighborhoods are among the individual events we have been able to uncover by cross referencing these three different modes of seeing in Aleppo.

Our case studies show that the use of high and low resolution satellite imagery, in combination with YouTube videos recorded by citizen journalists in Aleppo, provide a means of navigating the city in the midst of ongoing war. ${ }^{5}$ Each of these three sources of data offers a different kind of information about the city, and each has a different set of limitations. Our aim is that our research will productively highlight, rather than obscure these limitations.

\section{Visualizing Conflict: Possibilities for Urban Research}

The Conflict Urbanism projects in Colombia and Aleppo exemplify two challenges of analysis and visualization often critical for urban research. In Aleppo, through satellite imagery and YouTube videos we created data for anal-

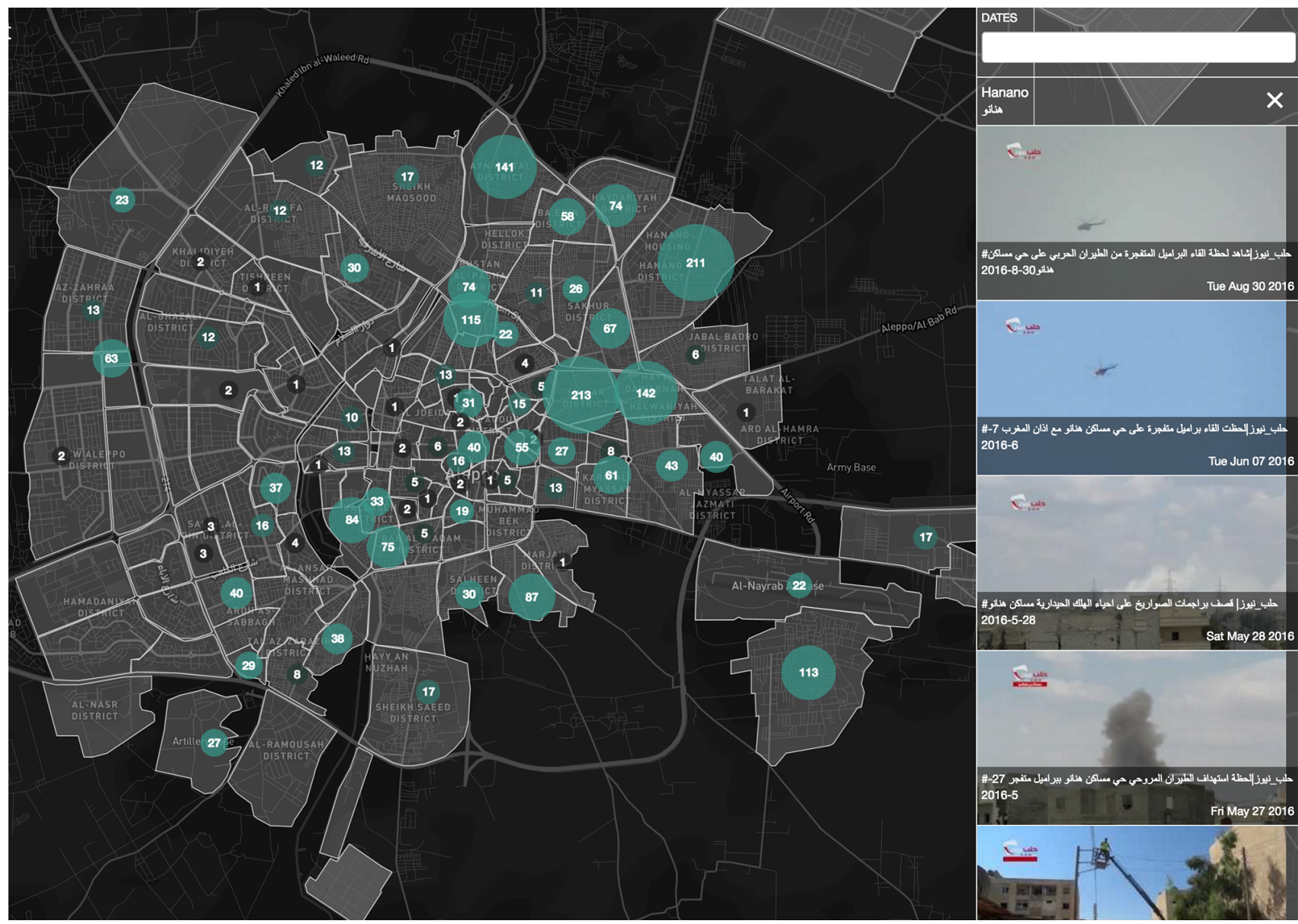

Figure 7. Interactive map with videos from three of the most highly cited YouTube channels geolocated to neighborhoods in Aleppo.

\footnotetext{
${ }^{5}$ View from Above, Conflict Urbanism: Aleppo. http://c4sr.columbia.edu/conflict-urbanism-aleppo/view-from-above.html.
} 
ysis which did not previously exist. Even in the era of 'big data' many of the most pressing urban issues are often those for which there is little or no recorded information. Experimental approaches such as the ones used in the Aleppo project can produce new tools that allow unconventional sources of information to become sources for research. In contrast, the work on Colombia was aided by the presence of a large but incomplete dataset. Resisting the temptation to present a comprehensive narrative with incomplete data, the project examines this one dataset very thoroughly, documenting its strengths as well as its limitations and using it as a lens to show the intricate pathways that people take in the midst of conflict. Both projects strive to responsibly produce and work with multiple new forms of data, specially data about the urban dynamics of conflict.

\section{Acknowledgments}

\section{Conflict Urbanism: Colombia is}

- Center for Spatial Research: Laura Kurgan and Juan Francisco Saldarriaga

- Universidad de Los Andes: Angelika Rettberg

- With: Dare Brawley, Anjali Singhvi, Patrick Li, Stella loannidou, Mike Howard and Jeevan Farias

\section{Conflict Urbanism: Aleppo is}

- Center for Spatial Research: Laura Kurgan, Grga Basic, Dare Brawley, Madeeha Merchant, Jamon Van Den Hoek

- With: Nadine Fattaleh, Mike Howard, Michael James Storm, Violet Whitney, and Carmelo Ignaccolo

\section{Conflict of Interests}

The authors declare no conflict of interests.

\section{References}

Cosgrove, D., \& Fox, W. L. (2010). Photography and flight. Reaktion Books.

Graham, S. (2010). Cities under siege: The new military urbanism. New York: Verso.

Kurgan, L. (2013). Close up at a distance: Mapping, technology, and politics. Brooklyn, NY: Zone Books.

Misselwitz, P., \& Rieniets, T. (Eds.). (2006). City of collision: Jerusalem and the principles of conflict urbanism. Basel: Birkhäuser.

Weizman, E. (2014). Introduction: Forensis. In Forensic Architecture, A. Franke, E. Weizman, \& Haus der Kulturen der Welt (Eds.), Forensis: The architecture of public truth (pp. 9-32). Berlin: Sternberg Press.

\section{About the Authors}

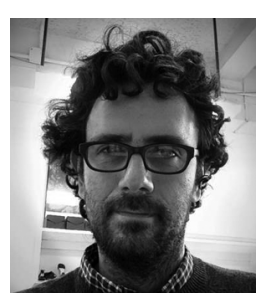

Juan Francisco Saldarriaga is an Associate Research Scholar at the Center for Spatial Research at Columbia University and an Adjunct Assistant Professor of Urban Planning and Architecture at the Graduate School of Architecture, Planning and Preservation (GSAPP). He does research at the intersection of data, GIS, urbanism, architecture and the humanities and teaches graduate level seminars on mapping, advanced GIS and data visualization.

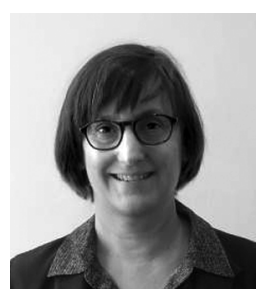

Laura Kurgan is an Associate Professor of Architecture at the Graduate School of Architecture Planning and Preservation at Columbia University, where she directs the Visual Studies curriculum, and the Center for Spatial Research. She is the author of Close Up at a Distance: Mapping, Technology, and Politics (Zone Books, 2013). From 2004-2015, she founded and directed the Spatial Information Design Lab at GSAPP.

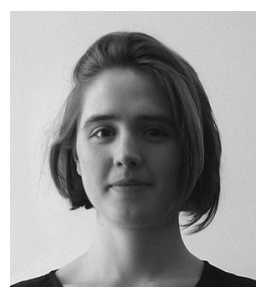

Dare Brawley manages the Architecture, Urbanism and the Humanities initiative of the Center for Spatial Research at the Columbia University Graduate School of Architecture, Planning and Preservation. Her research deals with open data and public policy, digital pedagogies, and the vexed cartographies of conflict urbanism. Her work has been exhibited and published by the Storefront for Art and Architecture, The Architectural League, the Lincoln Institute of Land Policy, and in Interboro Partner's The Arsenal of Inclusion and Exclusion. 